\title{
Poly (ethylene terephthalate) recycling for high value added textiles
}

\author{
Sang Ho Park and Seong Hun Kim ${ }^{*}$
}

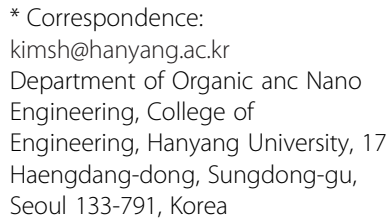

* Correspondence: kimsh@hanyang.ac.kr Department of Organic anc Nano Engineering, College of Engineering, Hanyang University, 17 Haengdang-dong, Sungdong-gu, Seoul 133-791, Korea

\begin{abstract}
This study reviews the problems in the use and disposal of poly (ethylene terephthalate) (PET) and includes the concise background of virgin and recycled PET as well as their possible applications. The current state of knowledge with respect to PET recycling method is presented. Recycling of PET is the most desirable method for waste management, providing an opportunity for reductions in oil usage, carbon dioxide emissions and PET waste requiring disposal because of its non-degradability. Advanced technologies and systems for reducing contamination, mechanical and chemical recycling, and their applications are discussed, and the possibility of diverting the majority of PET waste from landfills or incineration to recycling is suggested.

Keywords: Polyethylene terephthalate; Mechanical recycle; Chemical recycle
\end{abstract}

\section{Introduction}

Poly (ethylene terephthalate) (PET), commonly referred to as 'polyester' in the textile industry, is considered to be one of the most important thermoplastic polyesters (Incornato et al. 2000). It is widely used for various applications such as bottles, fibers, moldings, and sheets because of its excellent tensile and impact strength, clarity, processability, chemical resistance, and thermal stability (Pawlak et al. 2000; Kong and Hay 2003; Avila-Orta et al. 2003). The PET fiber patented originally by DuPont (DuPont, 1997) dominates over 50\% of the world synthetic fiber market. In the late 1950s, PET film was developed and used for X-ray, photographic, and cassette recording films as well as flexible packing materials. Blow molding techniques began to be used to stretch PET, which produced three dimensional structures, resulting in the rapid growth of light and unbreakable PET bottle manufacturers in the early 1970s (Wyeth and Roseveare 1973).

These developments in the PET manufacturing process resulted in a diversity of industrial applications, leading to increased consumer demand for PET, and many global companies produced PET with different trade names (Carraher 2000). The total world production capacity of PET amounted to 64,400 kilotons per year (kt/year) in 2008. Polyester fibers and bottles accounted for most of the total world production, representing $63.5 \%$ and $30.3 \%$, respectively, while the production of polyester film and engineering resin accounted for 6.2\% (Cischem. Com Co., Ltd. Publication 2010). PET goods such as fibers and bottles have become a major part of human life, and their production and consumption have increased continuously. 
PET, unlike natural polymers, is a non-degradable polymer in the natural environment (Edge et al. 1991), leading to environmental pollution when it is discarded after use. Procedures to enable biological degradation of PET are both complicated and expensive (PACIA 2002). Therefore, PET waste management with upcycling concept has become an important social issue because of PET's increasing consumption and nonbiodegradability. The upcycling concept by recycling is shown in Figure 1. Extensive utilization of PET results in waste management difficulties. Landfill of PET is undesirable because of space limitations and ground pollution. Incineration is also not the preferred option, because of the inevitable emission of toxic gases that are generated from the decomposition of PET molecular chains and residual additives, although incineration produces energy.

Because of this problem, recycling of PET is considered to be the best upcycling way to manage PET waste economically (Farahat et al. 2000). The recycling of PET is also an important concept with regard to the awareness of environmental concerns and conservation of scarce energy and feedstocks, which is related to national economy. The cost effective technology for PET recycling should be developed because virgin PET has a low and steady price.

Since the first recycling of PET in 1977 (Miller 2002), many studies have been conducted to investigate PET recycling methods (Helwani et al. 2009; Patterson 2007; Yoshioko et al. 1994, 2001), and the recovery rate of consumed PET has been consistently increasing. The world consumption of PET packaging is expected to about 19.1 million tons by 2017, with 5.2\% increase per year between 2012 and 2017 (Smithers Pira 2012). The majority of the recycled PET was converted into fibers as shown in Figure 2 and based on the report by Noone (Noone 2008). There are two kinds of PET fibers, partially oriented yarn (POY) and staple fibers. They are utilized for various end-use applications with different material properties. Therefore, the recycled PET staple fibers and POY are

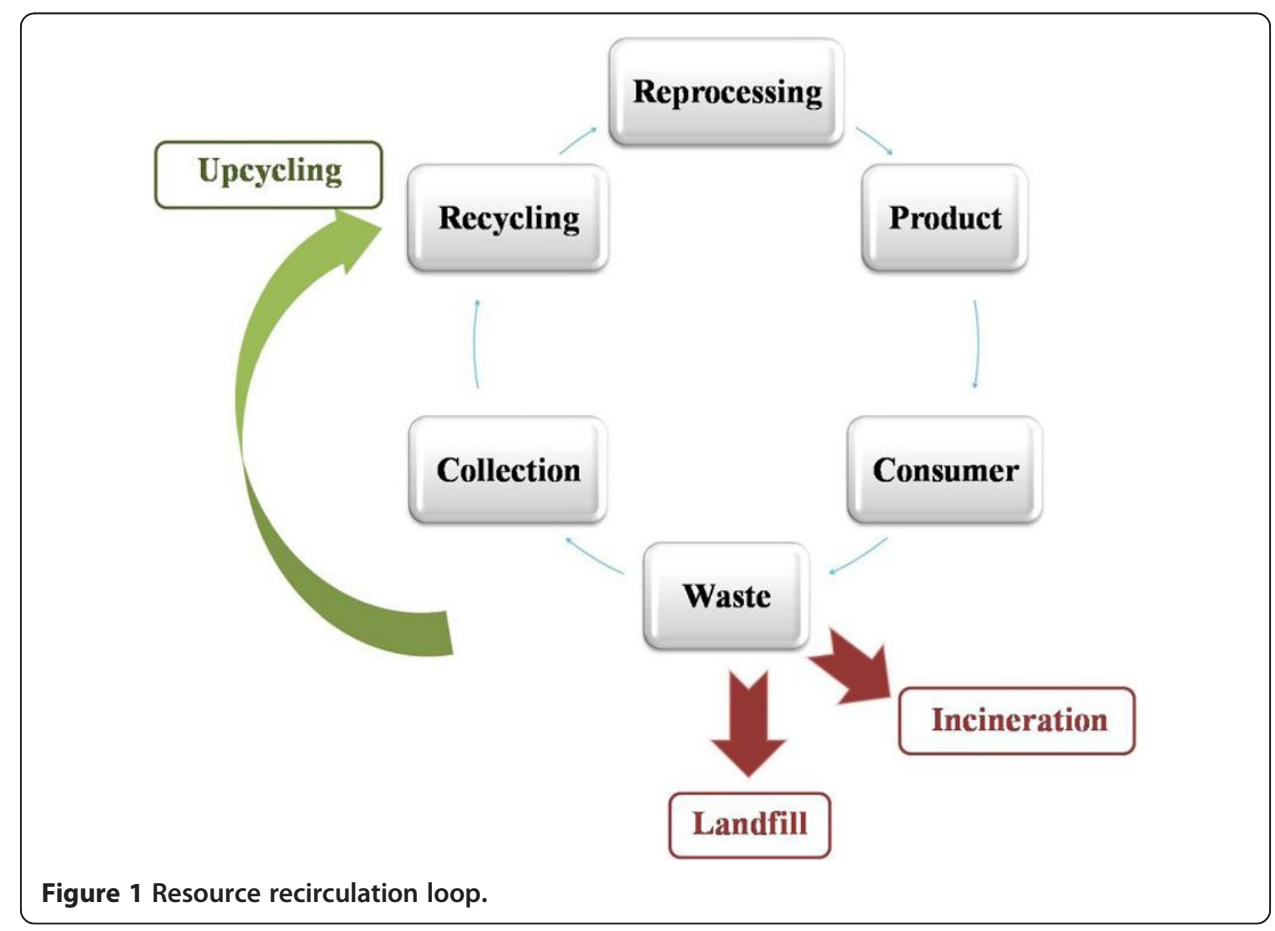




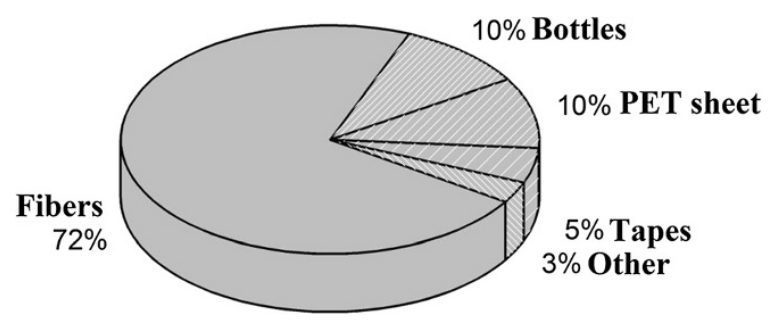

Figure 2 Applications of recycled PET flakes based on data from (Noone 2008).

very important because they play a crucial role as intermediate products in the nonwoven and textile industries.

PET waste can be recycled in many ways including chemical and mechanical methods. Hopewell (Hopewell et al. 2009) has summarized various terminologies used for plastic recycling. The primary recycling method is re-extrusion, the classical method of recycling PET. This method involves recycling of scrap materials to form original products. However, because various polymers and other materials such as paper, pigments, metals, and adhesives are used as plastic packing materials, this makes recycling by this method difficult. Although this method has the advantages of simplicity and low cost, it is not a popular method that requires uncontaminated scrap with only a single type of waste.

The secondary recycling is the mechanical recycling method, commercialized in the 1970s. This method is carried out by reprocessing PET waste to granules after separation of the polymer from contaminants. It is also called 'materials recycling', which includes sorting and separation of waste, washing for removal of dirt and contaminants, grinding and crushing, and reprocessing process (Aguada and Serrano 1999). The heterogeneity of the PET waste is the main issue for mechanical recycling because the complexity and contamination of the PET waste makes it difficult to recycle mechanically. The decline in the product quality is also the main disadvantage of mechanical recycling because the heat of fusion causes photo-oxidation, and mechanical stress results from the inverse reaction. Therefore, this recycling method is not used for making products that require high quality standards.

The third recycling, also called chemical recycling, has great potential because of the severe limitations of the mechanical recycling of PET wastes. Chemical recycling enables recovery of the petrochemical constituents of PET wastes, which can be utilized for remanufacturing PET products or other synthetic chemicals. It has not been cost effective to use this method because of the lower price of petrochemical feedstocks compared with the process prices for production of PET monomers or oligomers from PET waste (Patel et al. 2000). Chemical recycling has the advantage of reversing the energyintensive polymerization performed during the original manufacture of PET, which is important in terms of life-cycle assessment. PET wastes can be depolymerized by hydrolysis, methanolysis and glycolysis (Chen et al. 2001a; Kosmidis et al. 2001; Yamaye et al. 2002; Goje and Mishra 2003), and converted into PET resin or other unsaturated polyesters (Sinha et al. 2010), providing raw materials for a large variety of products.

The fourth recycling is the energy recovery method, which involves incineration of the PET waste. PET waste management by incineration generates thermal energy by recovering the chemical energy stored in PET wastes. It is considered to be an undesirable 
method because it causes air pollution and health risks from toxic gases generated during the incineration of PET wastes. Therefore, the discussion in this study focuses only on the mechanical and chemical recycling methods relevant to the management for PET wastes.

In this research, the current recycling systems and technologies for PET waste management are reviewed, and the manufacturing process for preparation of recycled PET fibers is discussed in terms of a sustainable textile industry.

\section{Poly (ethylene terephthalate) (PET)}

PET has been one of the most widely used engineering polymers during the past two decades because of its lightness, cheap and readily available feedstock, and low energy requirements for processing and fabrication. The two PET grades (fiber-grade PET and bottle-grade PET) are dominant in the global market. These two PET grades have different molecular weight or intrinsic viscosity (IV), optical properties and production recipes, which differ mainly in quantity and type of comonomers, stabilizers, metal catalyst, and colorants (Rieckmann and Volker 2003).

PET is produced by step-growth polycondensation from terephthalic acid (TPA) and ethylene glycol (EG), and the synthesis of PET involves two different starting reactions. One is the esterification reaction in which TPA is reacted with EG, forming bis (hydroxyethyl) terephthalate (BHET) as a prepolymer. The other is the transesterification reaction in which dimethyl terephthalate (DMT) is reacted (Ravindranath and Mashelkar 1986). These two different starting reactions are shown in Figure 3. The transesterification process was much preferred in the early years of PET production because of the easy purification of DMT by distillation. However, the majority of processes for PET production have shifted from DMT to TPA as the feedstock since highly purified TPA has been obtained for the first time at an industrial scale by recrystallization in the late

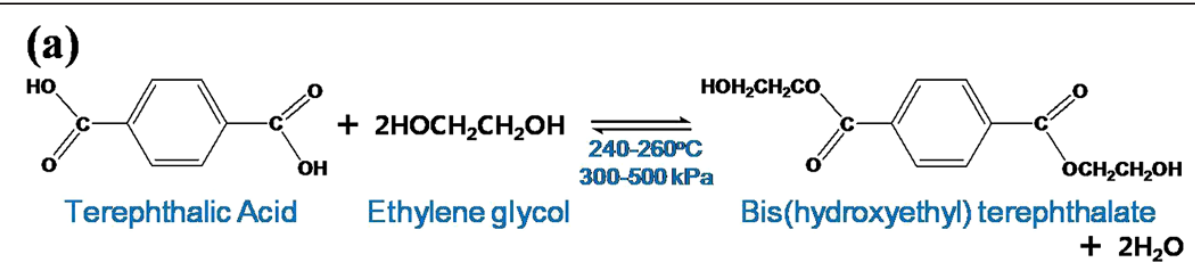

(b)

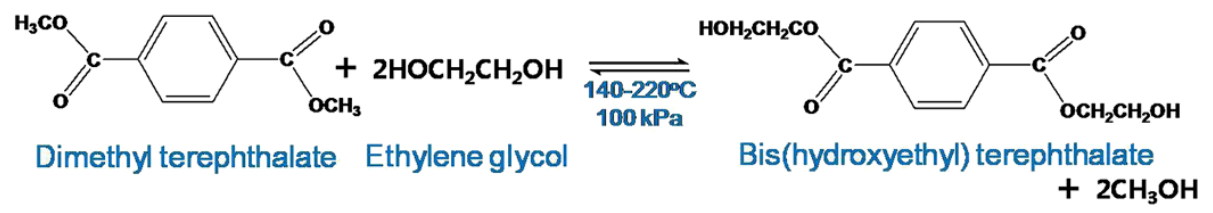

(c)

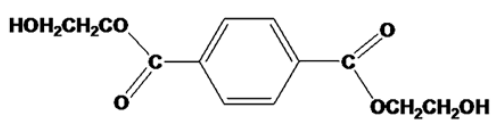

Bis(hydroxyethyl) terephthalate

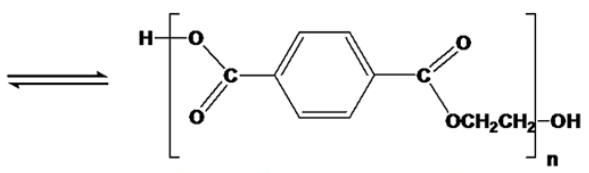

Polyethylene Terephthalate

Figure 3 PET synthesis reactions: (a) esterification, (b) transesterification, and (c) eventual condensation reactions. 
1960s. The PET, up to this stage, is appropriate for applications such as fibers and recording tapes for which high molecular weight or viscosity is not required. PET with high molecular weight and viscosity for bottles or technical yarns is produced by further polycondensation through the solid-state polymerization process.

Processed PET has been used in a wide range of applications because of its low cost (Thompson et al. 2009), remarkable tensile strength, chemical resistance, clarity, and reasonable thermal stability (Caldicott 1999). More than $60 \%$ of the PET produced worldwide is applied in the textile industry. Other applications include recording tapes, X-ray films, and thermoformed products such as housewares, automobiles, lighting products, sporting goods, and food packaging (Carraher 2000; ILSI Europe Report Series 2000). In the food packaging industry, PET has mainly been utilized for beverages because of its glass-like transparency and adequate gas barrier properties. Its toughness also leads to lightweight and unbreakable containers with large capacity (Welle 2011).

This widespread application of PET results in the unavoidable creation of large amounts of PET waste, creating serious difficulties in maintaining a clean environment. With increasing environmental awareness in our society, the recycle method is the most viable option for PET waste management. The recycling of PET waste can be carried out in many ways as described in the next chapter.

\section{Recycled PET}

The extensive use of PET products leads to waste management difficulties. PET products have a slow decomposition rate (Edge et al. 1991), creating ongoing environmental pollution problems after use. There are many studies describing methods for successful PET recycling, and the minimum requirements that recycled PET flakes should meet are reported in Table 1 (Miller 2002; Awaja and Pavel 2005; Pawlak et al. 2000). Recycled PET should fulfill the following quality objectives for suitability in high-value applications. The quality objectives are color separation, minimum contamination, intrinsic viscosity close to the original values, and consistent batch-to-batch quality.

\section{Contamination}

Contamination of postconsumer PET is the major factor that contributes to the deterioration of its physical and chemical properties during reprocessing (Giannotta et al. 1994).

Table 1 Minimum requirements for PET flakes to be reprocessed (Awaja and Pavel 2005; Miller 2002; Pawlak et al. 2000)

\begin{tabular}{ll}
\hline Properties & Values \\
\hline Intrinsic viscosity & $>0.7\left(\mathrm{dlg}^{-1}\right)$ \\
Melting temperature & $>240\left({ }^{\circ} \mathrm{C}\right)$ \\
Water content & $<0.02$ wt $\%$ \\
Flake size & $0.4 \mathrm{~mm}<$ suitable value $<8 \mathrm{~mm}$ \\
Dye content & $<10 \mathrm{ppm}$ \\
Yellow index & $<20$ \\
Metal content & $<3 \mathrm{ppm}$ \\
Polyvinyl chloride content & $<50 \mathrm{ppm}$ \\
Polyolefin content & $<10 \mathrm{ppm}$ \\
\hline
\end{tabular}


In general, contamination cannot be admitted for fiber or bottle applications because of fiber breakage and aesthetic problems. Minimization of contamination leads to better quality of recycled PET (Torres et al. 2000).

\section{Acids contamination}

The chain scission reactions of the ester linkages of PET are catalyzed by acidic compounds, generated from contaminants at the high temperatures used during extrusion in the reprocessing. Typical contaminants such as PVC, glue, dirt, ethylene vinyl acetate (EVA), and paper, and the acidic compounds that catalyze the hydrolysis of the PET ester linkages, are shown in Figure 4 (Koo et al. 2013). The most harmful acidic compounds are acetic acid (produced by EVA from the cap liners), rosin acid and abietic acid $\left(\mathrm{C}_{19} \mathrm{H}_{29} \mathrm{COOH}\right.$; produced by adhesives from the label), and hydrochloric acid (produced by PVC flakes from PVC bottles). These acids play a role as catalysts for PET chain scission reactions during reprocessing (Scheirs 1998; Cardi et al. 1993; Paci and La Mantia 1998).

\section{Moisture}

Moisture contamination must be below $0.02 \%$ to prevent molecular weight reduction by hydrolysis (Scheirs 1998). Seo and Cloyd (Seo and Cloyd 1991) reported that there were two degradation stages by moisture contamination during reprocessing. The first stage of degradation was attributed to hydrolysis from residual water in the recycled PET, while the second stage was attributed to thermooxidative chain scission with a lower degradation rate than the first stage. The conventional solution is to dry the PET before reprocessing by using special driers such as the Sikoplast ${ }^{\text {tix }} \mathrm{T} 800$ drier. Commercial dryers are available for successful PET drying at $150^{\circ} \mathrm{C}$ for 4 hours (Scheirs 1998).

\section{Labels and adhesives}

Ultrathin polyethylene (PE) films are used for PET labels without any adhesive assistance, and they are removed by flotation during the separation process. The separation

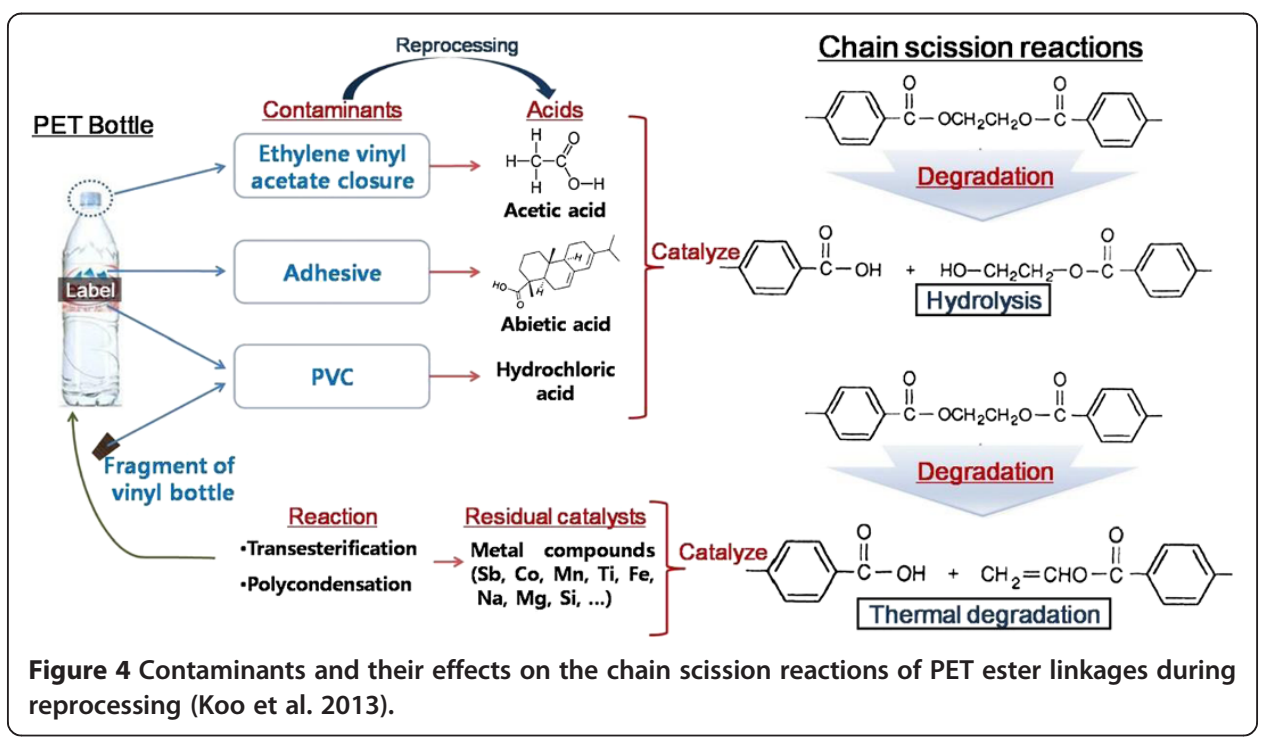


of PE films becomes difficult when heavy overprinting is applied, resulting in an increase in the label density.

Three types of adhesives (Scheirs 1998) are utilized for unmodified labels instead of water-soluble adhesives such as dextrin, starch, and casein glues, which have poor adhesion to PET plastics. The first type is synthetic glues based on polyvinyl acetate or ethylene vinyl acetate, and these glues are broken down in water during the recycling process. Some glue may be retained in the PET and be incorporated into the recycled resin. The second type is thermal adhesives based on ethylene vinyl acetate, which are completely uninfluenced by the washing process. These glues can soften during shredding or the label removal process because of their low Tm, resulting in glue residue being attached to the PET. The last type is alkali-soluble glue. When it is exposed to $\mathrm{NaOH}$ solution (2 wt\%), this glue crumbles and separates from the PET. This glue is the preferred option except for its higher cost compared with traditional adhesives.

\section{Coloring contaminations}

Dyes for color bottles cause undesirable coloring during reprocessing, and printed ink labels can also discolor PET flakes in the washing process. Progress in sorting and washing techniques may reduce this color contamination in bottle recycling (Awaja and Pavel 2005).

\section{Metal interactions}

In general, recycled PET includes various metal catalyst residues that can be used for the PET manufacturing process, as summarized in Table 2 (Richard et al. 1992). These metal ions, which promote transesterification and polycondensation reactions, lead to chemical heterogeneity of the recycled PET that affects the melt rheological behavior.

\section{Acetaldehyde}

Acetaldehyde is the major by-product of PET degradation reactions. The reaction by the recombination of vinyl ester and hydroxyl endgroups restores the molecular weight of the PET; however, this reaction also unfortunately produces vinyl alcohol, which forms acetaldehyde by tautomerization. This acetaldehyde can migrate into the final product, which is a major concern for food applications. Fortunately, acetaldehydes are highly volatile, so their production can be minimized by processing under vacuum or drying. Another method for the minimization of acetaldehyde production was reported by Villain et. al. (Villain et al. 1995). Various stabilizers such as 4-aminobenzoic acid,

Table 2 Various metal ions in recycled PET and their origins (Richard et al. 1992)

\begin{tabular}{lll}
\hline Metal ions & Concentration $(\mathbf{p p m})$ & Origin \\
\hline $\mathrm{Sb}$ & $220-240$ & Polycondensation catalyst \\
$\mathrm{Co}$ & $50-100$ & Polycondensation catalyst \\
$\mathrm{Mn}$ & $20-60$ & Transesterification catalyst \\
$\mathrm{Ti}$ & $0-80$ & Polycondensation catalyst \\
$\mathrm{Fe}$ & $0-6$ & Incorporated during washing \\
$\mathrm{Na}, \mathrm{Mg}, \mathrm{Si}$ & - & Food additives \\
\hline
\end{tabular}


diphenylamine and 4,5-dihydroxybenzoic acid have been incorporated into PET to minimize the amount of acetaldehyde formation.

\section{Other contaminants}

People use PET bottles for storing dangerous materials such as detergents, fuel, and pesticides, which can be a hazard to public health if these materials remain after PET recycling (Demertzis et al. 1997). An increase in public awareness about the dangers of storing these materials in PET bottles is required for application of recycled PET.

\section{Mechanical recycling}

Mechanical recycling, also known as material recycling, involves many treatments and operations. The steps in mechanical recycling include separation of waste, washing to remove dirt and contaminants, crushing and grinding to decrease PET particle size, reextrusion, and reprocessing for production of new PET goods (Babinchak 1991). It is possible to recycle thermoplastic PET mechanically, while it is impossible to recycle thermoset PET because it cannot be remolded by heat. It is difficult to recycle contaminated PET waste mechanically because of the complexity of the waste stream. The major issues for mechanical recycling are the heterogeneity of the PET waste and deterioration of the product properties each time it is recycled. Small amounts of another polymer incorporated in the PET matrix may significantly change the properties of PET, disturbing its possible use in conventional applications. In addition, PET, like most polymers, is degraded during use because of various factors such as temperature, ultraviolet radiation, oxygen, ozone, and mechanical stresses, leading to altered properties and reduced performance of recycled PET compared with virgin PET. Another difficulty with recycled PET is an undesirable grey color, resulting from the presence of PET waste made from the same resin (Bartolome et al. 2012). High-quality recycled PET is achieved when successful separation is conducted prior to the remolding step.

PET flakes can be reprocessed into fibers by the melt extrusion system. Currently, there are two methods for the production of recycled PET fibers from mechanical recycling. One is the more common method where PET flakes are extruded directly into fibers, and the other is the conversion method where PET flakes are reprocessed into granules or pellets and then melt extruded into fibers. Compared with chemical recycling, the mechanical recycling of PET has many advantages, such as the relative simplicity of the process, low investment cost, utilization of readily available equipment, flexibility of feedstock supply, and little negative environmental effect. However, mechanical recycling can degrade the printability or dyeability of the final product because of the cyclic and linear oligomers generated (Dulio et al. 1995). The yellowing of mechanically recycled PET is also a significant problem because of the intramolecular cross-linking and oxidation reactions (Edge et al. 1996). Above all, the major disadvantage of mechanical recycling is the reduction of the molecular weight or intrinsic viscosity, by thermal and hydrolytic degradation. Both the academic and industrial fields have explored methods for maintaining the molecular weight or intrinsic viscosity during the mechanical recycling process of postconsumer PET. 


\section{Chemical recycling}

Chemical recycling is accompanied by transformation of the PET chain. By means of polymer chain scission, the PET polymer can be broken down into either its monomers or its oligomers and other chemicals (Chen et al. 2001b; Kosmidis et al. 2001; Yamaye et al. 2002; Goje and Mishra 2003; Kao et al. 1998; Carta et al. 2003). It is more cost consuming than the mechanical recycling, and there is no economic incentive because of the higher manufacturing cost of chemically recycled PET compared with virgin PET. Chemical recycling needs to be implemented at a large scale to become economically feasible. Compared with other recycling methods, chemical recycling is the only method that conforms to 'sustainability' principles (Bartolome et al. 2012), because it produces original raw materials. In addition, extra resources for producing PET are unnecessary in the chemical recycling of PET (Achilias and Karayannidis 2004). The commercially available chemical recycling technologies contain glycolysis (Ikladious 2000; Chen et al. 2001b; Pardal and Tersac 2007; Kosmidis et al. 2001), hydrolysis (Carta et al. 2003; Goto et al. 2002; Kurokawa et al. 2003; Genta et al. 2007), methanolysis (Goto et al. 2002; Kurokawa et al. 2003; Genta et al. 2007), and aminolysis (Spychaj et al. 2001; Shukla and Harad 2006) reactions. The classification of chemical recycling with each reaction product is shown in Figure 5. These chemical recycling technologies are discussed in detail below.

\section{Glycolysis}

Since the chemical recycling of PET by glycolysis was first developed by McDowell et al. in 1965 (McDowell and Klusio 1965), this process has been widely utilized on a commercial scale. The PET polymer is decomposed through the glycolysis reaction by glycol in the presence of transesterification catalysts. This reaction mainly yields BHET for polyester condensation, and the glycolysis reaction scheme is shown in Figure 6 (Bartolome et al. 2012). Numerous studies have investigated glycolysis of PET because of the advantages of this process, including simplicity, flexibility, and low capital costs. Another advantage is that the glycolysis process can be easily applied to conventional PET production plants (Scheirs 1998). The recovered BHET can be incorporated into virgin BHET, and this mixture can be utilized for two different PET production processes (DMT-or TPA-based). Chemical recycling by glycolysis uses ethylene glycol (Baliga and Wong 1989; Chen et al.

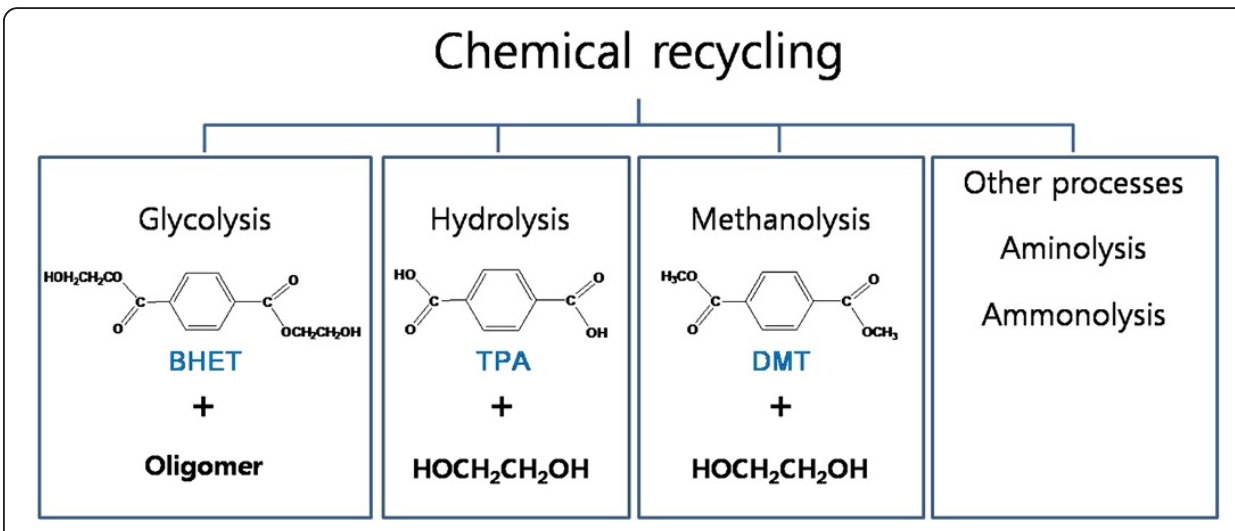

Figure 5 Classification of the chemical recycling methods with the products of each reaction. 


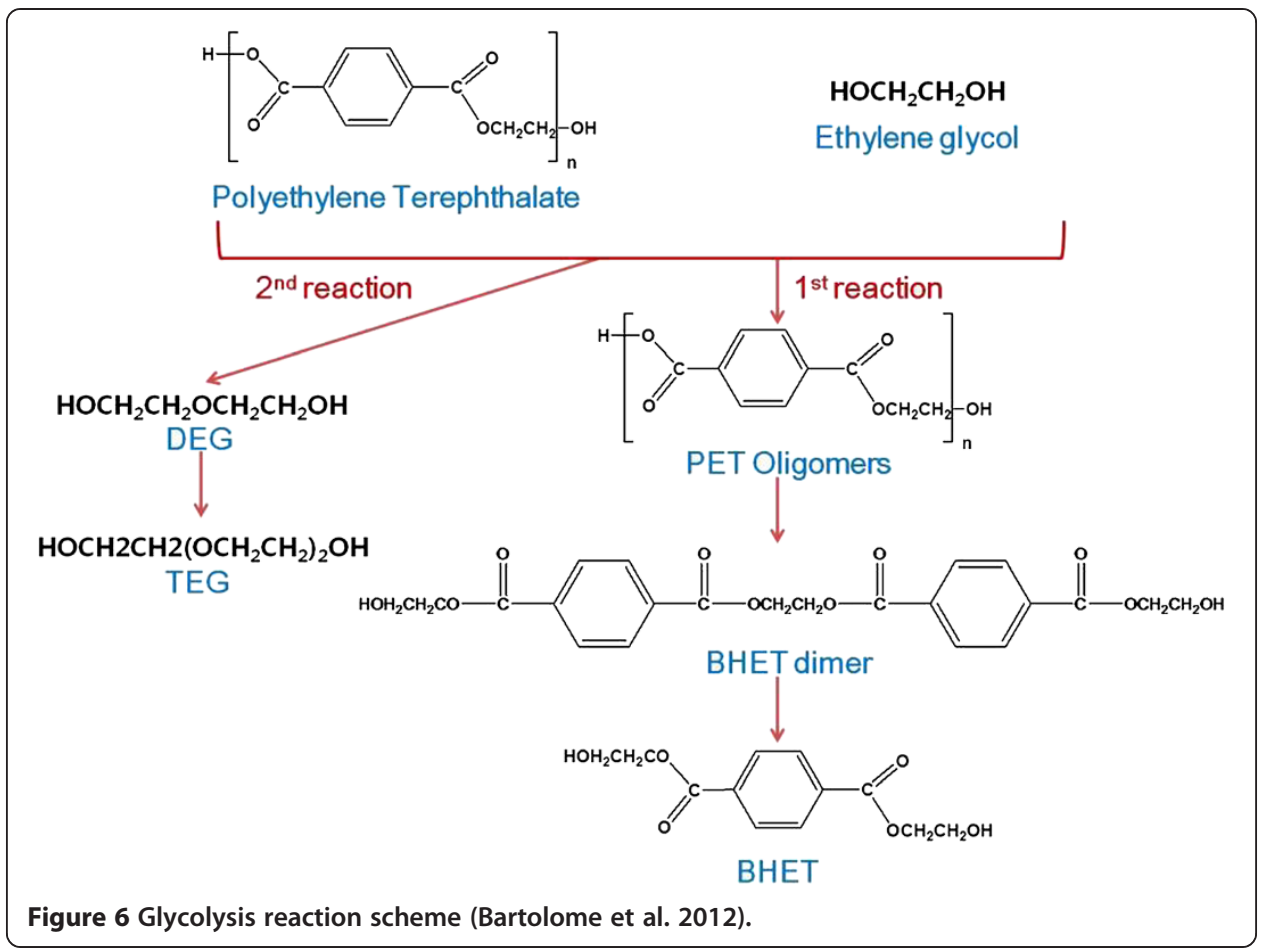

1991), diethylene glycol (Karayannidis et al. 2006; Vaidya and Nadkarni 1987a, 1987b), propylene glycol (Vaidya and Nadkarni 1987a, 1987b, 1987c; Guclu et al. 1998), or triethylene glycol (Ozturk and Guclu 2005). Glycolysis cannot produce clear virgin PET because it is a partial depolymerization to the intermediate BHET, and colorants or dyes are not removed. Glycolysis yields not only BHET but also significant amounts of other oligomers (Scheirs 1998), and this makes it difficult to apply for synthesis of specific desired products. Furthermore, it is known from studies on PET glycolysis kinetics that the glycolysis rate is very slow without a catalyst, and complete depolymerization of PET to BHET is impossible (Campanelli et al. 1994a; Chen and Chen 1999). Therefore, many researchers have investigated methods for enhancing the glycolysis rate and BHET monomer yield by application of efficient catalysts and optimization of the reaction conditions. Another approach is the development of products made from glycolysis without the separation oligomer (Grzebienek and Wesolowski 2004). Since the beginning of glycolysis research, the BHET monomer yield and reaction time have improved continuously from just $65 \%$ yield over 8 hours reaction time to at least $90 \%$ with the remarkably reduced reaction time of about 30 minutes (Bartolome et al. 2012).

The most intensively studied method for increasing glycolysis rate is transesterification catalysis. The metal-based catalyst promotes the glycolysis reaction mechanisms (Shukla and Harad 2005; Pingale et al. 2010). The free electron pair of the ethylene glycol attacks the carbonyl carbon of the PET ester group, and then the covalent bonding between the hydroxyethyl group of ethylene glycol and the carbonyl carbon of PET is formed, which leads to breakage of the long chain into short chain oligomers and creation of BHET. The glycolysis rate and BHET monomer yield are dependent on various reaction parameters such as temperature, PET/ethylene glycol ratio, and type and 
amount of catalysts. A number of studies are summarized in Table 3, detailing the optimum glycolysis conditions and reaction parameters obtained (Dulio et al. 1995; Pingale et al. 2010; Xi et al. 2005; Troev et al. 2003; Shukla and Kulkarni 2002; Shukla et al. 2008; Imran et al. 2011; Wang et al. 2009; Yue et al. 2011).

\section{Hydrolysis}

The next chemical recycling method is hydrolysis, which produces TPA and ethylene glycol under high-pressure (1.4-2 $\mathrm{MPa}$ ) and high-temperature $\left(200-250^{\circ} \mathrm{C}\right)$ conditions with a long depolymerization time. In general, hydrolysis is not used commercially in food-grade production, because of the cost associated with purification of the recycled TPA (Sinha et al. 2010). The hydrolysis of PET can be performed as acid hydrolysis, alkaline hydrolysis, and neutral hydrolysis.

Acid hydrolysis is carried out by using sulfuric or nitric acid to yield TPA. This process becomes very costly because of the necessity of recycling large quantities of concentrated sulfuric acid and purifying ethylene glycol containing sulfuric acid. Yoshioka (Yoshioko et al. 1994) reported an effective hydrolysis process using $7 \mathrm{M}$ sulfuric acid, resulting in good yields of TPA and ethylene glycol. The hydrolysis reaction using nitric acid also produces TPA and ethylene glycol, and the ethylene glycol is simultaneously oxidized to oxalic acid, which is more expensive than TPA and ethylene glycol.

Table 3 Various reaction parameters for PET glycolysis ((a) Pingale, et al. 2010; (b) Xi, et al. 2005; (c) Troev et al. 2003; (d) Shukla and Kulkarni 2002; (e) Shukla et al. 2008; (f) Imran, et al. 2011; (g) Wang et al. 2009; (h) Yue et al. 2011)

\begin{tabular}{|c|c|c|c|c|c|c|}
\hline Catalysts & $\begin{array}{l}\text { BHET } \\
\text { yield (\%) }\end{array}$ & $\begin{array}{l}\text { Temp. } \\
\left({ }^{\circ} \mathrm{C}\right)\end{array}$ & $\begin{array}{l}\text { Time } \\
\text { (min) }\end{array}$ & $\begin{array}{l}\text { Ethylene glycol } / \text { PET } \\
\text { mol ratio }\end{array}$ & $\begin{array}{l}\mathrm{PET} / \text { Catalyst } \\
\text { weight ratio }\end{array}$ & Refs \\
\hline Lithium chloride & 59.46 & 197 & 480 & 10 & 0.005 & (a) \\
\hline Zinc chloride & 73.24 & & & & & \\
\hline Didymium chloride & 71.01 & & & & & \\
\hline Magnesium chloride & 55.67 & & & & & \\
\hline Ferric chloride & 56.28 & & & & & \\
\hline Zinc acetate & 85.6 & 196 & 180 & $5(w / w)$ & 0.01 & (b) \\
\hline Zinc acetate & 62.8 & 200 & 150 & 2.77 & 0.003 & (c) \\
\hline Titanium phosphate & 97.5 & & & & & \\
\hline Zinc acetate & 62.51 & 190 & 480 & 6 & 0.005 & (d) \\
\hline Lead acetate & 61.65 & & & & & \\
\hline Sodium carbonate & 61.5 & & & & & \\
\hline Sodium bicarbonate & 61.94 & & & & & \\
\hline$\beta$-zeolite & 66 & 196 & 480 & 6 & 0.01 & (e) \\
\hline ү-zeolite & 65 & & & & & \\
\hline Zinc oxide on silica & $\sim 85$ & 300 & 80 & 11 & 0.01 & $(f)$ \\
\hline $\begin{array}{l}\text { Magnesium oxide on silica } \\
\text { nanoparticle }\end{array}$ & $>90$ & & & & & \\
\hline Ionic liquids & - & 190 & 120 & $10(w / w)$ & 0.05 & (g) \\
\hline [bmim] $\mathrm{OH}$ & 71.2 & 190 & 120 & 10 & 0.05 & (h) \\
\hline
\end{tabular}


Alkaline hydrolysis has the economic advantage of using cheap $\mathrm{NaOH}$ as the catalyst for hydrolytically recycled PET, with no high-pressure equipment necessary. However, recycled PET by alkaline hydrolysis contains up to $40 \mathrm{wt} \%$ impurities, while mechanical and other recycling methods contain 1-10 wt\% of contaminants. Alkaline hydrolysis also converts ethylene glycol to $\mathrm{CO}_{2}$ and oxalic acid, which adds value and makes the process economically feasible because oxalic acid is more valuable than ethylene glycol. Furthermore, the final product is colorless even when using green PET bottle feedstock, implying that this process effectively oxidizes the green dye in the PET feedstock.

Since the development of hydrolytic techniques under alkaline or acidic condition, hydrolytic scission of PET under neutral conditions has been developed. The PET can be depolymerized in a high-pressure autoclave with excess water, resulting in high-purity TPA and ethylene glycol. The complete depolymerization of PET by this method is performed within 2 hours at $265^{\circ} \mathrm{C}$ (Cardi et al. 1993), and advanced methods (Campanelli et al. 1994b) using metal salts as catalysts are also being investigated.

\section{Methanolysis}

Methanolysis is a simple alcoholysis treatment, which produces DMT and ethylene glycol. The PET is dissolved and partially glycolyzed by the methanolysis, resulting in DMT and ethylene glycol, and then DMT is purified by crystallization and distillation (Scheirs 1998). Typical PET feedstocks for methanolysis are postconsumer films, plant waste, fiber waste, and bottle scraps. Because it is much easier to purify DMT compared with BHET, PET feedstocks with lower quality are acceptable in the methanolysis process as compared with the glycolysis process, and other products such as ethylene glycol and methanol are easily recycled and recovered (Goto et al. 2002; Kurokawa et al. 2003; Genta et al. 2007; Guclu et al. 2003). Although methanolysis has high processing costs, its relatively low feedstock costs compensate for the relatively high processing costs because methanolysis is more tolerant of contamination. However, the main feedstock for PET production is purified TPA, not DMT, which is the major product of methanolysis. The conversion of DMT to TPA by hydrolysis adds considerable expense to the methanolysis process. A novel methanolysis technique, which has lower conversion costs and high yields, has been developed by Eastman Kodak and DuPont (Scheirs 1998).

\section{Aminolysis}

Aminolysis of PET involves the reaction of PET with amine, and terephthalamide is the product obtained. There are many studies concerning the depolymerization of PET waste using different amines such as allylamine, morpholine, hydrazine, and polyamines (Spychaj et al. 2001; Shukla and Harad 2006). This process is not commercially utilized in PET recycling. However, partial aminolysis has found an application in the improvement of PET properties in the manufacture of fibers (Collins et al. 1991). The reaction was generally conducted using primary amine aqueous solutions such as methylamine, ethylamine, and ethanolamine at $20-100^{\circ} \mathrm{C}$ (Collins et al. 1991). Anhydrous nbutylamine was also used as the aminolytic agent (Collins et al. 1991). 


\section{Application of recycled PET}

\section{Fiber applications for mechanically recycled PET}

There are several major application areas for the PET textile industry, such as staple fibers, filament, nonwoven fabric and fiberfill. Generally, recycled PET has been utilized for fibers of more than 6 denier, while the largest market for the PET fiber industry (clothing and apparel applications) is in the 1.5-3 denier range. A novel processing technology was developed in 1993, which enabled recycled PET to be used in fibers much finer than 3 denier, and this fiber obtained from recycled PET has been commercialized (Scheirs 1998). These fibers require high-quality feedstock, and postconsumer PET flakes used for these fibers should have consistent intrinsic viscosity around $0.7 \mathrm{dlg}^{-1}$.

Traditionally, recycled PET has not been widely used for filament production because of contaminants leading to breakage of the filament. Melt filtration of the PET is carried out to achieve high quality of the resin. Nonwoven fabrics, used as filters and absorbents, are prepared by spun bounding technology. In the production of recycled PET, nonwoven, cleaned PET bottle flake is dried, crystallized and incorporated into the extruder. The melt-spun filaments are spread and distributed on a screen belt under strong vacuum, and the fibrous materials are compressed into a mat for web-forming. Fiberfill is utilized for various applications such as filling materials and insulant in sleeping bags, pillows, and bedding. These applications allow the use of colored PET flake and require PET with intrinsic viscosity in the range of 0.58-0.65 $\mathrm{dlg}^{-1}$.

\section{Applications for chemically recycled PET}

Chemically recycled PET can be used for applications in the manufacture of polyurethane (Lee et al. 1994, 1995; Vaidya and Nadkarni 1990) and unsaturated polyester resin (Abdel-Azim et al. 1994; Lu and Kim 2001; Suh et al. 2000). Polyurethane is a widely used polymer for various applications such as insulation, seating materials, and artificial leather (Park et al. 2013). The oligoesters obtained from PET glycolysis can be further reacted with aliphatic diacids to form polyester polyols, which can be utilized as the starting material for polyurethane synthesis (Nikles and Farahat 2005). The PET oligoesters can be directly reacted with diisocyanate for preparation of polyurethane (Ikladious 2000; Chen et al. 2001b; Pardal and Tersac 2007; Kosmidis et al. 2001). Mercit (Mercit and Akar 2001) reported on the synthesis of new urethane oil from glycolysis-treated PET waste. The glycolysis of PET using different diol compounds produces different glycolysis products, leading to a broad spectrum of physical properties of the polyurethane obtained from these products.

Unsaturated polyester resins have been used extensively as a matrix for highperformance fiber-reinforced polymer composites, and they can be synthesized from virgin material or from recycled PET (Lu and Kim 2001). Pimpan et al. (Pimpan et al. 2003) investigated the synthesis and curing process of unsaturated polyester resins from PET waste bottles. This study (Pimpan et al. 2003) discovered that the type of glycol, such as ethylene glycol, propylene glycol, or diethylene glycol, had a crucial effect on the properties of the glycolysis products. The results from this study (Pimpan et al. 2003) also showed that the type of bottle did not significantly affect the properties of the unsaturated polyester resins, implying that no separation bottle is needed. 


\section{Conclusion}

In summary, PET recycling is one strategy for PET waste management with economic and environmental advantages. Extensive studies concerning the synthesis, properties, and processing of virgin PET as well as their composites for high performance are reported in this paper. In addition, publication reviews as described above indicate that many scientific technologies have been developed in the field of PET recycling. In particular, this review has focused on the advantages and disadvantages of mechanical and chemical recycling methods with an emphasis on industrial applications. It is possible to use mechanically recycled PET for various applications in the textile industry, and the products obtained from chemical recycling of PET can be also used as feedstocks for polyurethane and unsaturated polyester resins. With these efforts to increase the use and specification of recycled grade PET as a replacement for virgin PET, the recycling of PET waste is an effective method for enhancing the environmental performance of the PET fashion and textile industries.

\section{Acknowledgement}

This research was supported by Ministry of Trade, Industry and Energy of Korea (Project No. 10035180), National Research Foundation of Korea (Project Nos. 2012-047656 and 2012-0001597), and Korea Ministry of Environment (Project No. 2013001470001).

Received: 23 January 2014 Accepted: 27 February 2014

Published online: 01 July 2014

\section{References}

Abdel-Azim AA, Mahmoud BH, Farahat MS (1994) Electromechanical effects in ferroelectric liquid crystalline polymers. Polym Adv Technol 5:269-274

Achilias D, Karayannidis G (2004) The Chemical Recycling of PET in the Framework of Sustainable Development. Water Air Soil Poll 4(4-5):385-396

Aguada J, Serrano D (1999) Feedstock Recycling of Plastic Wastes, The Royal Society of Chemistry. Chapter 1 Introduction, United Kingdom, pp 1-29. ISBN 0-85404-531-7

Alghatta H, Cobror S, Severini T (1997) New Technology for Solid-state Polymerization of Polymers: Polyethylene terephthalate-Solid-state Polyaddition. Polymers Adv Technol 8:161-168

Avila-Orta CA, Medellin-Rodriquez FF, Wang ZG, Navarro-Rodriquez D, Hsiao BS, Yeh F (2003) On the nature of multiple melting in poly (ethylene terephthalate) (PET) and its copolymers with cyclohexylenedimethylene terephthalate (PET/CT). Polymer 44:1527-1535

Awaja F, Pavel D (2005) Recycling of PET. Eur Polym J 41:1453-1477

Babinchak S (1991) Recycling Must Work. ChemTech 21(12):728

Baliga S, Wong WT (1989) Depolymerization of poly (ethylene terephthalate) recycled from post-consumer soft-drink bottles. J Polym Sci A Polym Chem 27:2071-2082

Bartolome L, Imran M, Cho BG, Al-Masry WA, Kim DH (2012) Recent Developments in the Chemical Recycling of PET, Material Recycling - Trends and Perspectives, Dr. DimitrisAchilias., InTech, from http://www.intechopen.com/books/ material-recycling-trends-and-perspectives/recent-developments-in-the-chemical-recycling-of-pet. ISBN: 978-953-51-0327-1

Bizarria MTM, De Giraldi MALF, Carvalho CM, Velasco JID, Avila MA, Mei LHI (2007) Morphology and thermomechanical properties of recycled PET-organoclay nanocomposites. J Appl Polym Sci 104:1839-1844

Caldicott R (1999) The Basics of Stretch Blow Molding PET Containers. Plast Eng 55(1):35-40

Campanelli JR, Cooper DG, Kamal MR (1994a) Catalyzed hydrolysis of polyethylene terephthalate melts. J Appl Polym Sci 53:985-991

Campanelli JR, Kamal MR, Cooper DG (1994b) Kinetics of glycolysis of poly (ethylene terephthalate) melts. J Appl Polym Sci 54(11):1731-1740

Campanelli JR, Kamal MR, Cooper DG (1993) A kinetic study of the hydrolytic degradation of polyethylene terephthalate at high temperatures. J Appl Polym Sci 48:443-451

Cardi N, Po R, Giannotta G, Occhiello E, Garbassi F, Messina G (1993) Chain extension of recycled poly (ethylene terephthalate) with 2,2'-Bis (2-oxazoline). J Appl Polym Sci 50:1501-1509

Carta D, Cao G, D'Angeli C (2003) Chemical recycling of poly (ethylene terephthalate) (PET) by hydrolysis and glycolysis. Environ Sci Pollut Res 10(6):390-394

Carraher CE (2000) Polymer chemistry, 5th edn. Marcel Dekker Inc, New York

Chen CH, Chen CY, Lo Y, Mao C, Liao WT (2001a) Studies of glycolysis of poly (ethylene terephthalate) recycled from postconsumer soft-drink bottles. II. Factorial experimental design. J Appl Polym Sci 80(7):956-962

Chen CH, Chen CY, Lo YW, Mao CF, Liao WT (2001b) Studies of glycolysis of poly (ethylene terephthalate) recycled from postconsumer soft-drink bottles. I. Influences of glycolysis conditions. J Appl Polym Sci 80(7):943-948

Chen J, Chen L (1999) The glycolysis of poly (ethylene terephthalate). J Appl Polym Sci 73(1):35-40

Chen JY, Ou YC, Lin CC (1991) Depolymerization of poly (ethylene terephthalate) resin under pressure. J Appl Polym Sci 42:1501-1507

Cischem. Com Co., Ltd. Publication (2010) The world market analysis of PET value chain 
Collins MJ, Zeronian SH, Marshall ML (1991) Analysis of the Molecular Weight Distributions of Aminolyzed Poly (Ethylene Terephthalate) by Using Gel Permeation Chromatography. J Macromol Sci: Part A - Chem 28:775-792

Demertzis PG, Johansson F, Lievens C, Franz R (1997) Studies on the development of a quick inertness test procedure for multi-use PET containers-sorption behaviour of bottle wall strips. Packag Technol Sci 10:45-58

Dulio V, Po R, Borrelli R, Guarini A, Santini C (1995) Characterization of low-molecular-weight oligomers in recycled poly (ethylene terephthalate). Die Angewandte Makromolekulare Chemie 225:109-122

Publications DP (1997) Technical data sheets on Melinar PET resins

Edge M, Hayes M, Mohammadian M, Allen NS, Jewitt TS, Brems K, Jones K (1991) Aspects of poly (ethylene terephthalate) degradation for archival life and environmental degradation. Polym Degrad Stab 32(2):131-153

Edge M, Wiles R, Allen NS, McDonald WA, Mortlock SV (1996) Characterisation of the species responsible for yellowing in melt degraded aromatic polyesters - I: Yellowing of poly (ethylene terephthalate). Polym Degrad Stab 53:141-151

Farahat MS, Abdel-Azim AA, Abdel-Raowf ME (2000) Modified unsaturated polyester resins synthesized from poly (ethylene terephthalate) waste, 1. Synthesis and curing characteristics. Macromol Mater Eng 283:1-6

Genta M, Iwaya T, Sasaki M, Goto M (2007) Supercritical methanol for polyethylene terephthalate depolymerization: Observation using simulator. Wastemanage 27(9):1167-1177

Giannotta G, Po G, Cardi N, Tampellini E, Occhiello E, Garbassi F, Nicolais L (1994) Processing effects on poly (ethylene terephthalate) from bottle scraps. Polym Eng Sci 34:1219-1223

Goje AS, Mishra S (2003) Chemical kinetics, simulation, and thermodynamics of glycolytic depolymerization of poly (ethylene terephthalate) waste with catalyst optimization for recycling of value added monomeric products. Macromol Mater Eng 288:326-336

Goto M, Koyamoto H, Kodama A, Hirose T, Nagaoka S (2002) Depolymerization of polyethylene terephthalate insupercritical methanol. J Phys: Condens Matte 14(44):11427-11430

Grzebienek K, Wesolowski J (2004) Glycolysis of PET waste and the use of glycolysis products in the synthesis of degradable co-polyesters. Fibres Textile East Eur 12(2):19-22

Guclu G, Kasgoz A, Ozbudak S, Ozgumus S, Orbay M (1998) Glycolysis of poly (ethylene terephthalate) wastes in xylene. J Appl Polym Sci 69(12):2311-2319

Guclu G, Yalcinyuva T, Ozgumus S, Orbay M (2003) Hydrolysis of waste polyethylene terephthalate and characterization of products by differential scanning calorimetry. Thermochim Acta 404:193-205

Helwani Z, Othman M, Aziz N, Kim J, Fernando W (2009) Solid heterogeneous catalysts for transesterification of triglycerides with methanol: A review. Appl Catal A Gen 363(1-2):1-10

Hopewell J, Dvorak R, Kosior E (2009) Plastics recycling: challenges and opportunities. Philos Trans Royal Soc B: Biol Sci 364:2115-2126

IKladious NE (2000) Recycling of poly (terephthalate): Identification of glycolysis product. J Elastomers and Plastics 32(2):140-151

ILSI Europe Report Series (2000) Packaging Materials: 1. Polyethylene terephthalate (PET) for food packaging applications. ISLI Press, Brussels. ISBN 1-57881-092-2

Imran M, Lee K, Imtiaz Q, Kim B, Han M, Cho B, Kim D (2011) Metal-oxide-doped silica nanoparticles for the catalytic glycolysis of polyethylene terephthalate. J Nanosci Nanotechnol 11(1):824-828

Incornato L, Scarfato P, Di Maio L, Acierno D (2000) Structure and rheology of recycled PET modified by reactive extrusion. Polymer 41:6825-6831

Kao C, Cheng W, Wan B (1998) Investigation of alkaline hydrolysis of polyethylene terephthalate by differential scanning calorimetry and thermogravimetric analysis. J Appl Polym Sci 70:1939-1945

Karayannidis G, Nikolaidis A, Sideridou I, Bikiaris D, Archilias D (2006) Chemical recycling of PET by glycolysis: Polymerization and characterization of the dimethacrylated glycolysate. Macromol Mater Eng 291(11):1338-1347

Kong Y, Hay JN (2003) Multiple melting behaviour of poly (ethylene terephthalate). Polymer 44:623-633

Koo HJ, Chang GS, Kim SH, Hahm WG, Park SY (2013) Effects of recycling processes on physical, mechanical and degradation properties of PET yarns. Fibers and Polymers 14:2083-2087

Kosmidis VA, Achilias DS, Karayannidis GP (2001) Poly (ethylene terephthalate) recycling and recovery of pure terephthalic acid. Kinetics of a phase transfer catalyzed alkaline hydrolysis. Macromol Mater Eng 286(10):640-647

Kracalik M, Mikesova J, Puffr R, Baldrian J, Thomann R, Friedrich C (2007a) Effect of 3D structures on recycled PET/ organoclay nanocomposites. Polym Bull 58:313-319

Kracalik M, Pospisil L, Slouf M, Mikesova J, Sikora A, Simonik J, Fortelny I (2008) Recycled poly (ethylene terephthalate) reinforced with basalt fibres: Rheology, structure, and utility properties. Polym Compos 29:437-442

Kracalik M, Studenovsky M, Mikesova J, Sikora A, Thomann R, Friedrich C, Frotelny I, Simonik J (2007b) Recycled PET nanocomposites improved by silanization of organoclays. J Appl Polym Sci 106:926-937

Kurokawa H, Ohshima MA, Sugiyama K, Miura H (2003) Methanolysis of polyethylene terephthalate (PET) in the presence of aluminiumtiisopropoxide catalyst to form dimethyl terephthalate and ethylene glycol. Polym Degrad Stab 79(3):529-533

Lee SC, Sze YW, Lin CC (1994) Polyurethanes synthesized from polyester polyols derived from PET waste. II. Thermal properties. J Appl Polym Sci 52:869-873

Lee SC, Sze YW, Lin CC (1995) Polyurethanes synthesized from polyester polyols derived from PET waste. III. Mechanical properties. J Appl Polym Sci 55:1271-1273

Lu M, Kim SW (2001) Unsaturated polyester resins based on recycled PET: Preparation and curing behavior. J Appl Polym Sci 80:1052-1057

McDowell JT, Klusio NC (1965) Process for reclaiming linear terephthalate polyester. US Patent, 3222299

Mcdowell CC, Partin JM, Freeman BD, McNeely GW (1999) Acetone solubility and diffusivity in poly (ethylene terephthalate) modified with low levels of 2,6-naphthalene dicarboxylic acid, isophthalic acid, and 2,5-bis-(4-carboxyphenyl)1,3,4-oxadiazole. J Membr Sci 163:39-49

Mercit O, Akar A (2001) Synthesis of urethane oil varnishes from waste poly (ethylene terephthalate). Macromol Mater Eng 286:513-515

Miller C (2002) Polyethylene Terephthalate. Waste Age 33(5):102-106 
Nikles DE, Farahat MS (2005) New motivation for the depolymerization products derived from poly (ethylene terephthalate) (PET) waste: A review. Macromol Mater Eng 290:13-30

Noone A (2008) Collected PET bottles. In: Proceedings of 13th International Polyester Recycling Forum

Ozturk Y, Guclu G (2005) Unsaturated polyester resins obtained from glycolysis products of waste PET. Polymer-Plastics Tech Eng 43(5):1539-1552

PACIA (2002) National Plastics Recycling Survey 2002., From http://www.pacia.org.au/reports/plasticsrecyclingsurveyarchive

Paci M, La Mantia FP (1998) Competition between degradation and chain extension during processing of reclaimed poly (ethylene terephthalate). Polym Degrad Stab 61:417-420

Paci M, La Mantia FP (1999) Influence of small amounts of polyvinylchloride on the recycling of polyethylene terephthalate. Polym Degrad Stab 63:11-14

Pardal F, Tersac G (2007) Kinetics of poly (ethylene terephthalate) glycolysis by diethylene glycol. Part II: Effect of temperature, catalyst and polymer morphology. Polym Degrad Stab 92(4):611-616

Park SH, Oh KW, Kim SH (2013) Reinforcement effect of cellulose nanowhisker on bio-based polyurethane. Compos Sci Technol 86:82-88

Patel M, von Thienen N, Jochem E, Worrell E (2000) Resources. Conserv Recycling 29:65-90

Patterson J (2007) Continuous depolymerization of poly(ethylene terephthalate) via reactive extrusion, March 2013. http://www.lib.ncsu.edu/resolver/1840.16/3783

Pawlak A, Pluta M, Morawiec J, Galeski A, Pracella M (2000) Characterization of scrap poly (ethylene terephthalate). Eur Polym J 36(9):1875-1884

Pegoretti A, Kolarik J, Peroni C, Migliaresi C (2004) Nano- and micro-mechanics of polymer blends and composites. Polymer 45:2751-2759

Pimpan V, Sirisook R, Chuayjuljit S (2003) Synthesis of unsaturated polyester resin from postconsumer PET bottles: Effect of type of glycol on characteristics of unsaturated polyester resin. J Appl Polym Sci 88:788-792

Pingale N, Palekar V, Shukla S (2010) Glycolysis of postconsumer polyethylene terephthalate waste. J Appl Polym Sci 115(1):249-254

Ravindranath K, Mashelkar A (1986) Polyethylene terephthalate - I. Chemistry, thermodynamics and transport properties. Chem Eng Sci 41:2197-2214

Richard RE, Boon WH, Martin-Shultz ML, Sisson EA (1992) In Andrews GD, Subramanian PM (eds) Incorporating postconsumer recycled polyethylene terephthalate; A new polyester resin; in Emerging Technologies in Plastics Recycling, 15th edn. ACS Symposium Series 513, p 196

Rieckmann TH, Volker S (2003) Modern polyesters: Chemistry and technology of polyesters and copolyesters. In: Scheirs J, Long TE (eds) Poly (ethylene terephthalate) polymerization - Mechanism, catalysis, kinetics, mass transfer and reactor design, 2nd edn. 2003 John Wiley \& Sons, Ltd, pp 31-115. ISBN: 0-471-49856-4

Scheirs J (1998) Polymer recycling, science, technology and application. John Wiley and Sons Ltd

Seo KS, Cloyd JD (1991) Kinetics of hydrolysis and thermal degradation of polyester melts. J Appl Polym Sci 42:845-850

Shukla SR, Harad AM (2005) Glycolysis of polyethylene terephthalate waste Journal of Applied Polymer Science. 97(2):513-517

Shukla SR, Harad AM (2006) Aminolysis of polyethylene terephthalate waste. Polym Degrad Stab 91(8):1850-1854

Shukla S, Kulkarni K (2002) Depolymerization of poly (ethylene terephthalate) waste. J Appl Polym Sci 85(8): $1765-1770$

Shukla S, Palekar V, Pingale N (2008) Zeolite catalyzed glycolysis of poly (ethyleneterephthalate) bottle waste. J Appl Polym Sci 110(1):501-516

Sinha V, Patel MR, Patel JV (2010) PET waste management by chemical recycling: A review. J Polym Environ 18:8-25

Pira S (2012) The future of global PET packaging to 2017, Market Reports

Spychaj T, Fabryey E, Spychaj S, Kacperski M (2001) Aminolysis and aminoglycolysis of waste poly (ethylene terephthalate). J Mater Cycles Waste Manage 3(1):24-31

Suh DJ, Park OO, Yoon KH (2000) The properties of unsaturated polyester based on the glycolyzed poly (ethylene terephthalate) with various glycol compositions. Polymer 41:461-466

Thompson R, Swan S, Moore C, VomSaal F (2009) Our plastic age. Philos Trans R Soc B 364:1973-1976

Torres N, Robin JJ, Bountvin B (2000) Study of thermal and mechanical properties of virgin and recycled poly (ethylene terephthalate) before and after injection molding. Eur Polym J 36:2075-2080

Troev K, Grancharov G, Tsevi R, Gitsov I (2003) A novel catalyst for the glycolysis of poly (ethylene terephthalate). J Appl Polym Sci 90(4):1148-1152

Vaidya UR, Nadkarni VM (1990) Unsaturated polyester resins and polyurethane elastomers and non-CFC rigid foams from poly (ethylene terephthalate) waste. Polymer Mater Sci Eng 63:1029-1033

Vaidya UR, Nadkarni VM (1987a) Unsaturated polyester resins from poly (ethylene terephthalate) waste. 1. Synthesis and characterization. Ind Eng Chem Res 26:194-198

Vaidya UR, Nadkarni VM (1987b) Unsaturated polyesters from PET waste: Kinetics of polycondensation. J Appl Polym Sci 34:235-245

Vaidya UR, Nadkarni VM (1987c) Polyester polyols for polyurethanes from pet waste: Kinetics of polycondensation. J Appl Polym Sci 35:775-785

Villain F, Coudane J, Vert M (1995) Thermal degradation of polyethylene terephthalate: Study of polymer stabilization. Polym Degrad Stab 49:393-397

Wang H, Liu Y, Li Z, Zhang X, Zhang S, Zhang Y (2009) Glycolysis of poly (ethylene terephthalate) catalyzed by ionic liquids. Eur Polym J 45(5):1535-1544

Welle F (2011) Twenty years of PET bottle to bottle recycling - An overview. Resour Conserv Recycl 55(11):865-875

Wyeth N, Roseveare RN (1973) Biaxially oriented poly (ethylene terephthalate) bottle. US Patents, 3733309

Xi G, Lu M, Sun C (2005) Study on depolymerization of waste poly (ethyleneterephthalate) into monomer of bis (2-hydroxyethyl terephthalate). Polym Degrad Stab 87(1):117-120

Yamaye M, Hashime T, Yamamoto K (2002) Chemical recycling of poly (ethylene terephthalate). 2. Preparation of terephthalohydroxamic acid and terephthalohydrazide. Ind Eng Chem Res 41(16):3993-3998 
Yesil S (2013) Effect of carbon nanotube reinforcement on the properties of the recycled poly (ethylene terephthalate)/ poly (ethylene naphthalate) (r-PET/PEN) blends containing functional elastomers. Mater Des 52:693-705

Yoshioko T, Sato T, Okuwaki A (1994) Hydrolysis of waste PET by sulfuric acid at $150^{\circ} \mathrm{C}$ for a chemical recycling. J Appl Polym Sci 52(9):1353-1355

Yoshioko T, Motoki T, Okuwaki A (2001) Kinetics of hydrolysis of poly (ethylene terephthalate) powder in sulfuric acid by a modified shrinking-core model. Ind Eng Chem Res 40(1):75-79

Yue Q, Wang Z, Zhang L, Ni Y, Jin Y (2011) Glycolysis of poly (ethylene terephthalate) (PET) using basic ionic liquids as catalysts. Polym Degrad Stab 96(4):399-403

doi:10.1186/s40691-014-0001-x

Cite this article as: Park and Kim: Poly (ethylene terephthalate) recycling for high value added textiles. Fashion and Textiles 2014 1:1.

Submit your manuscript to a SpringerOpen ${ }^{\odot}$ journal and benefit from:

- Convenient online submission

- Rigorous peer review

- Immediate publication on acceptance

- Open access: articles freely available online

- High visibility within the field

- Retaining the copyright to your article

Submit your next manuscript at $\boldsymbol{\nabla}$ springeropen.com 